\author{
E. Lunarska, O. Chernyayeva, D. Lisovytskiy \\ Institute of Physical Chemistry, Polish Academy of Sciences, Warsaw, Poland
}

\title{
HYDRIDE FORMATION AT CATHODIC CHARGING OF $\alpha$-Ti
}

\begin{abstract}
The hydrogen absorption and the formation of the hydride phase at cathodic polarization of annealed $\alpha$-Ti have been studied by the kinetic hydrogen extraction and by the X-ray diffraction methods. The electrochemical parameters of cathodic hydrogen charging have been selected in order to obtain the hydrogen present in the solid solution of $\alpha$-Ti lattice and the hydride phase to be formed. In $2 \mathrm{M} \mathrm{NaOH}$ solution, the hydride phase has been already formed at cathodic polarization lower than $1 \mathrm{~mA} / \mathrm{cm}^{2}$. In the case of $0.1 \mathrm{M} \mathrm{NaOH}$, the polarization regions (i) of hydrogen dissolution in the solid phase (ii) of hydride precipitation and (iii) of formation the increased amount of hydride phase have been distinguished in the course of application of increased cathodic polarization. Hydrogen dissolved in the metal lattice produces its dilatation, whereas presence of hydride phase causes the contraction of Ti lattice. Increased cathodic polarization causes the increase it the amount of hydride phase and the increase in the hydrogen content in $\mathrm{TiH}_{\mathrm{X}}$ phase as well.
\end{abstract}

Key words: $X$-ray diffraction, hydrogen thermal extraction, $\mathrm{NaOH}$ solutions, hydrogen solid solution, TiH $H_{X}$

\section{INTRODUCTION}

The maximum solubility of hydrogen occupying the tetrahedral holes in hcp $\alpha$-Ti attains $0.2 \mathrm{wt} \%$ at $300^{\circ} \mathrm{C}[1-3]$ and decreases to $0.001-0.003[1,2,4] \mathrm{wt}$. \% at RT. At the higher amount of absorbed hydrogen, the $\mathrm{TiH}_{\mathrm{x}}$ hydride of the fcc structure is formed $[1-3,5$ - 7]. Increase in the hydrogen content in that hydride causes the increase in its lattice parameter from about $4.407 \AA$ at $x=1.5$ to $4.434 \AA$ at $x=1.9$ [7] and to 4.44 [2] $-4.45 \AA$ [6] at $x=2$. However, the formation of the tetragonal structure of $\mathrm{TiH}_{2}$ hydride with the lattice parameters $\mathrm{a}=3.12 \AA$ and $\mathrm{c}=4.18 \AA$. [8] has been also reported [3, 7, 8]. Most studies have showed that hydrogen occupies the tetrahedral holes in hydride $[1-3,6]$, whereas the occupation of the both, tetrahedral and octahedral sites (depending on the hydrogen content and temperature) has been also suggested [9].

The minor change in the arrangement of the parent metal atoms at passing from the hcp lattice of $\alpha$-Ti to the fcc (or tetragonal) lattice of hydride and the occupation of the similar sites by hydrogen atoms in solid solution and in hydride structure cause the easiness of the solid solution-hydride transformation [1,3]. However, due to the difference in the lattice volume of both phases [7,9] the stresses have been introduced into the metals $[10,11]$ and into the hydride [4]. Defects formed in $\mathrm{Ti}$ at the hydride precipitation provide the trapping sites for the hydrogen atoms [10]. Therefore, the hydrogen as the atoms dissolved in the $\alpha$-Ti lattice, as trapped by defects and present as a constituent of the hydride phase may occur at the hydrogen charging of Ti. 
At exposition of $\alpha$-Ti to electrolytes, the formation of the continuous hydride layer [2, $4,12]$, the hydride precipitates [2, $13-15]$ or the hydrogen dissolution in the metal [10] may occur depending on the solution chemistry and $\mathrm{pH}$, the applied potential, used temperature and time. The hydrogen absorption, and thus the amount of hydride phase increases at increased cathodic polarization $[4,16]$ and time of charging [17]. In the case of acid solutions, the continuous surface layer of hydride is formed immediately [2, 4] at application of cathodic current below $5 \mathrm{~mA} / \mathrm{cm}^{2}$ [4]. Cathodic charging in the near neutral or alkaline electrolytes causes the lower hydrogen absorption and the formation of the needle hydride precipitates [13]. Decrease in the concentration of electrolyte also results in the lower hydrogen absorption [16].

The hydrogen charging of $\alpha$-Ti has been usually associated with the embrittlement of the metal $[2,11]$. The stated in [18] decrease in the shear modulus of $\alpha$-Ti may reveal its softening due to the hydrogen charging. However, it has been not clear whether decrease in the shear modulus occurs: 1) due to the intrinsic softening of $\alpha$-Ti lattice, 2) due to the formation of hydride phase having lower hardness [19] or 3) due to the increase in the dislocation density in the metal at the hydride formation.

Although the processes of the hydride formation and transformation has been intensively studied, the effect of dissolved hydrogen on the lattice parameters, stress and strain state and on the elastic properties of $\alpha$-Ti has not been fully recognized. The aim of present work was to study the effect of hydrogen dissolution and hydride precipitation on the state of the $\alpha$-Ti lattice at cathodic charging under the specially selected mild electrochemical parameters.

\section{MATERIALS AND EXPERIMENTAL PROCEEDURE}

The specimens were cut from the $1 \mathrm{~mm}$ sheet of $99.99 \%$ Ti. Since the hydrogen absorption has been found to be lower in alkaline than in acid solutions [13, 20], the $0.1 \mathrm{M}$ and $2 \mathrm{M} \mathrm{NaOH}$ have been selected as the test electrolytes. Solutions were prepared from the $\mathrm{NaOH}$ of spectral purity and the double distilled water. Specimens were polished with 600 mesh abrasive paper and immediately subjected to hydrogen charging. Hydrogen charging has been done galvanostatically in nondeaerated solutions at cathodic polarization within the range 0.1 to $1250 \mathrm{~mA} / \mathrm{cm}^{2}$ for 30 or $60 \mathrm{~min}$.

After hydrogen charging, specimens were rinsed, dried and cut. The parts of the same specimen were subjected to the measurements of the hydrogen extraction and to the X-ray diffraction. The kinetics of hydrogen thermal extraction was evaluated by the Hydrogen Analyzer AV $-1^{\circledR}[21]$. The amount of extracted hydrogen was recorded during the specimen heating up to $800^{\circ} \mathrm{C}$ with the constant heating rate $10^{\circ} / \mathrm{s}$. The X-ray diffraction spectra were recorded on Brucker AXS D8 diffractometer at $\mathrm{Cu}_{\mathrm{k}_{\alpha}}$ radiation. The phase composition and the lattice parameters of individual phases were evaluated form the analysis of the obtained spectra using the JCPDS PDF-2/2001 database [8]. In the case of hexagonal $\alpha$-Ti, the parameters $\boldsymbol{a}$ and $\boldsymbol{c}$ were calculated taking into account lines hk0 and 001 [22], respectively. The elastic strain of $\alpha$-Ti lattice in direction normal to the specimen surface, caused by hydrogen charging was calculated according to equation (1):

$$
\varepsilon=\frac{d_{\perp}-d_{0}}{d_{0}}
$$

where: $d_{0}$ and $d \perp-$ interplanar distance for the pure and for the hydrogen charged $\alpha$-Ti lattice, respectively. 


\section{RESULTS}

The hydrogen thermal desorption spectra obtained for cathodically charged specimens reveal the hydrogen extraction peaks at about $500^{\circ} \mathrm{C}$ and about $650^{\circ} \mathrm{C}$, the height of which depends on the applied electrochemical parameters.

The $650^{\circ} \mathrm{C}$ peak forms at cathodic polarization above $2 \mathrm{~mA} / \mathrm{cm}^{2}$ in $0.1 \mathrm{M} \mathrm{NaOH}$ for 30 min, cf. Fig. 1a. The peak height remains roughly constant with the increased cathodic polarization and then substantially increases at high polarization (Fig. 1b).
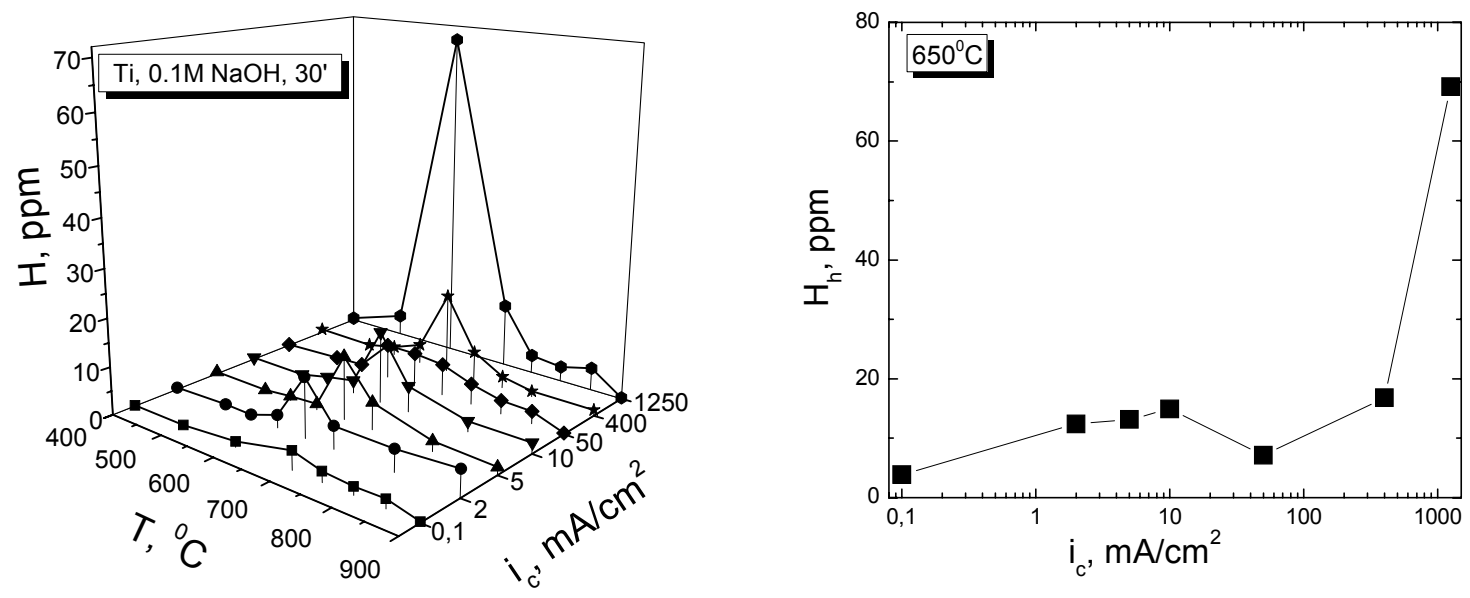

a

b

Fig.1. Effect of cathodic polarization on hydrogen extraction spectra (a) and on the height of the high temperature extraction peak (b) for Ti hydrogen charged in $0.1 \mathrm{M} \mathrm{NaOH}$ at different cathodic polarization

At polarization lower than $10 \mathrm{~mA} / \mathrm{cm}^{2}$ (Fig.2a), the peak height does not change with the time of polarization, whereas at higher cathodic polarization it increases with the prolongation of cathodic polarization (Fig. 2a). In the case of $2 \mathrm{M} \mathrm{NaOH}$, the $650^{\circ} \mathrm{C}$ peak has been formed at the lowest applied polarization and at the similar current it has been much higher than that formed at charging in $0.1 \mathrm{M} \mathrm{NaOH}$ solution (Fig. 2b).
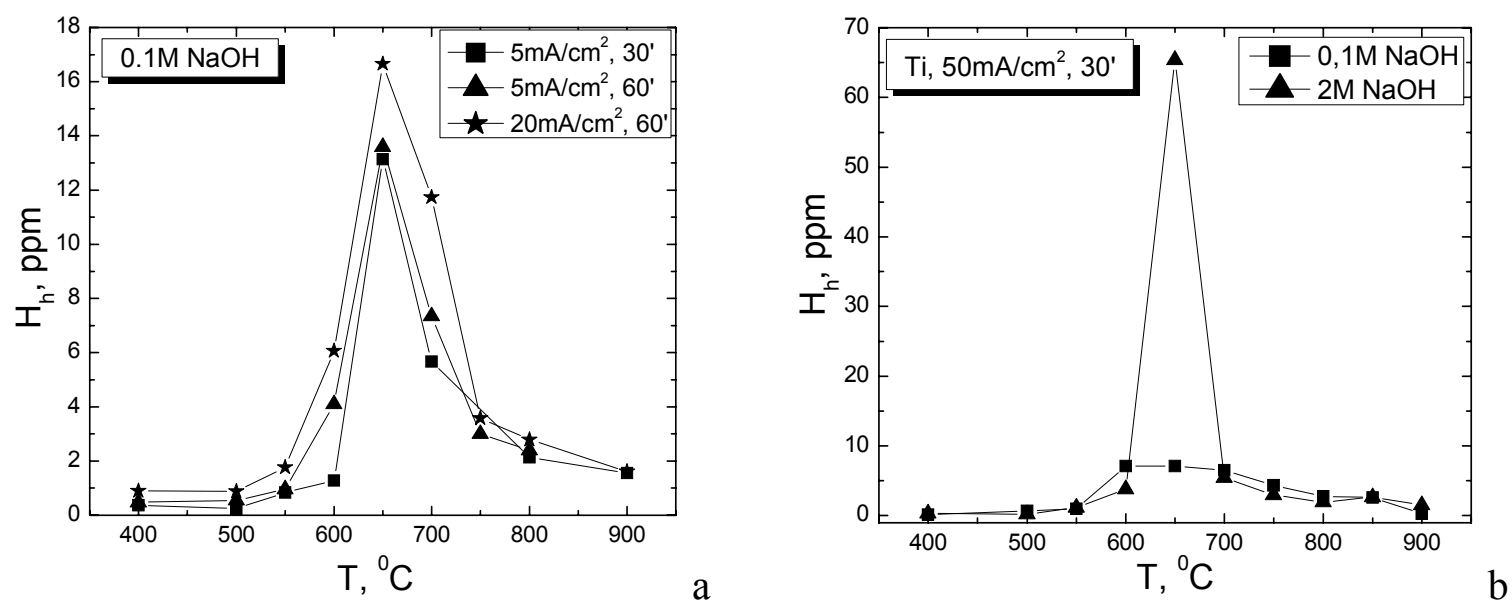

Fig. 2. Effect of the time of hydrogen charging and the applied cathodic polarization (a) and effect of the solution concentration (b) on the height of the high temperature extraction peak 
Beside the high temperature peak, the smaller but quite distinctive peak has been detected on the hydrogen extraction spectra at $500^{\circ} \mathrm{C}$. The height of that peak decreases with the increased cathodic polarization, up to the height corresponding to that measured for the as received material, cf. Fig. 3.

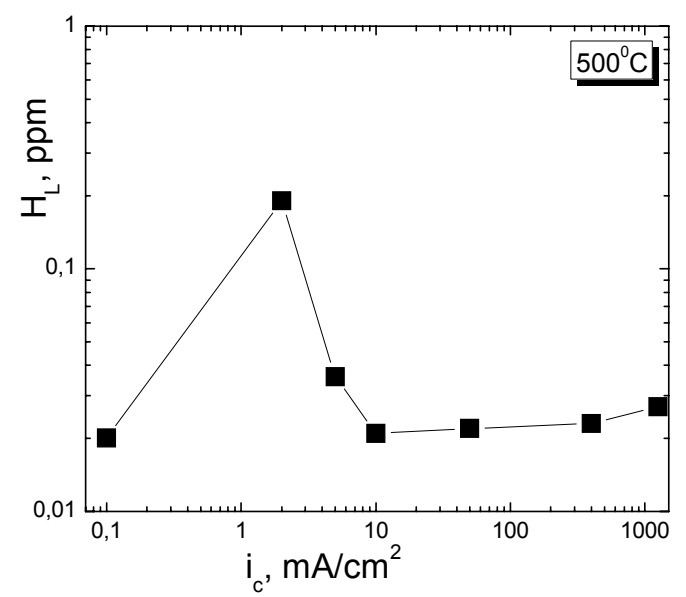

Fig. 3. Change of the height of the low temperature extraction peak with applied cathodic current density in $0.1 \mathrm{M}$ $\mathrm{NaOH}$

The obtained X-ray spectra reveal no effect on the phase composition at cathodic polarization lower than $5 \mathrm{~mA} / \mathrm{cm}^{2}$ in $0.1 \mathrm{M} \mathrm{NaOH}$ (Fig. 4a). Above that polarization, the hydride phase can be detected. The intensity of hydride lines corresponding to the amount of hydride phase remains constant at increased cathodic polarization and then rapidly increases (Fig. 4b).
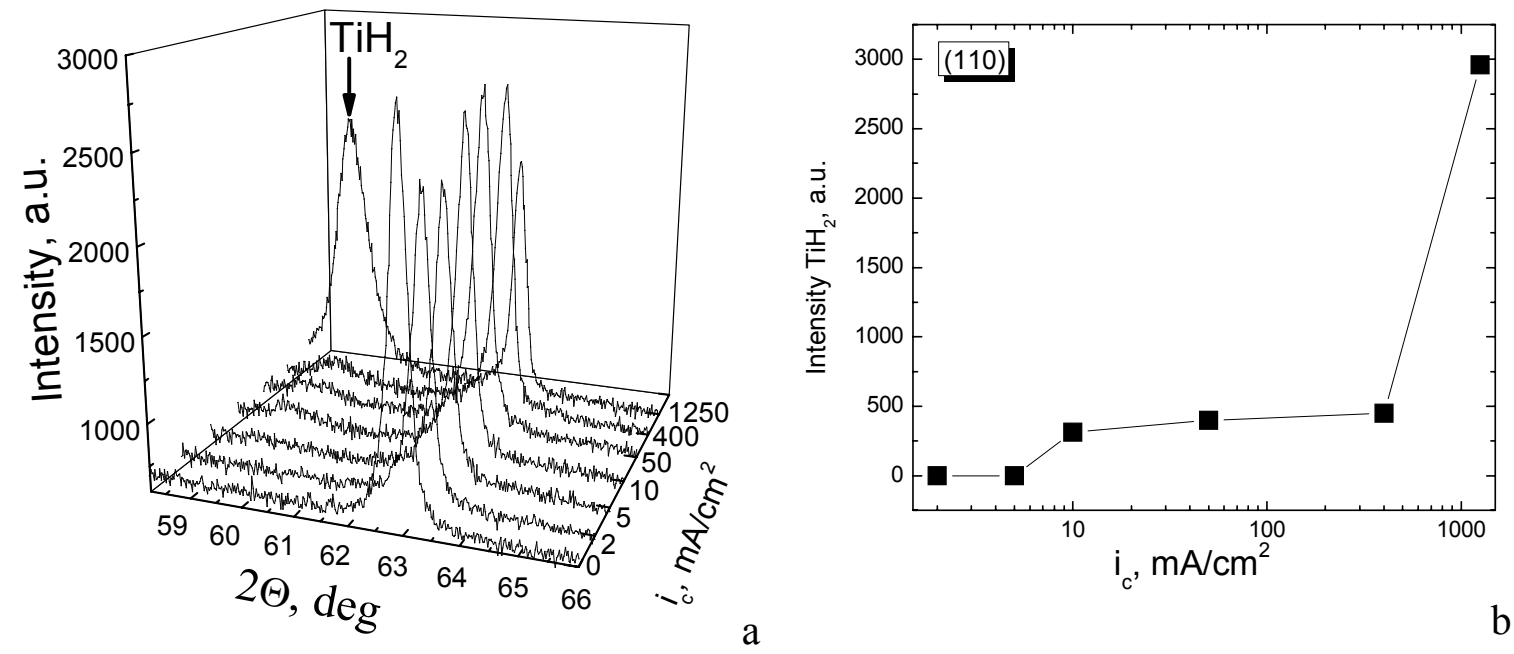

Fig. 4. Effect of cathodic polarization $(0.1 \mathrm{M} \mathrm{NaOH}, 30 \mathrm{~min})$ on X-ray spectra of $\mathrm{Ti}(\mathrm{a})$ and on the intensity of the hydride diffraction line revealing the change of the amount of the hydride phase (b)

Prolongation of charging time at low polarization does not cause the hydride formation, whereas at higher polarization the hydride line intensity increases with the time, revealing the increase in the hydride content, cf. Fig. 5a. At the similar cathodic polarization, the more intensive hydride formation takes place at charging in the $2 \mathrm{M} \mathrm{NaOH}$ than in the $0.1 \mathrm{M} \mathrm{NaOH}$ one (Fig. 5b) despite the higher $\mathrm{pH}$ in the first case. 

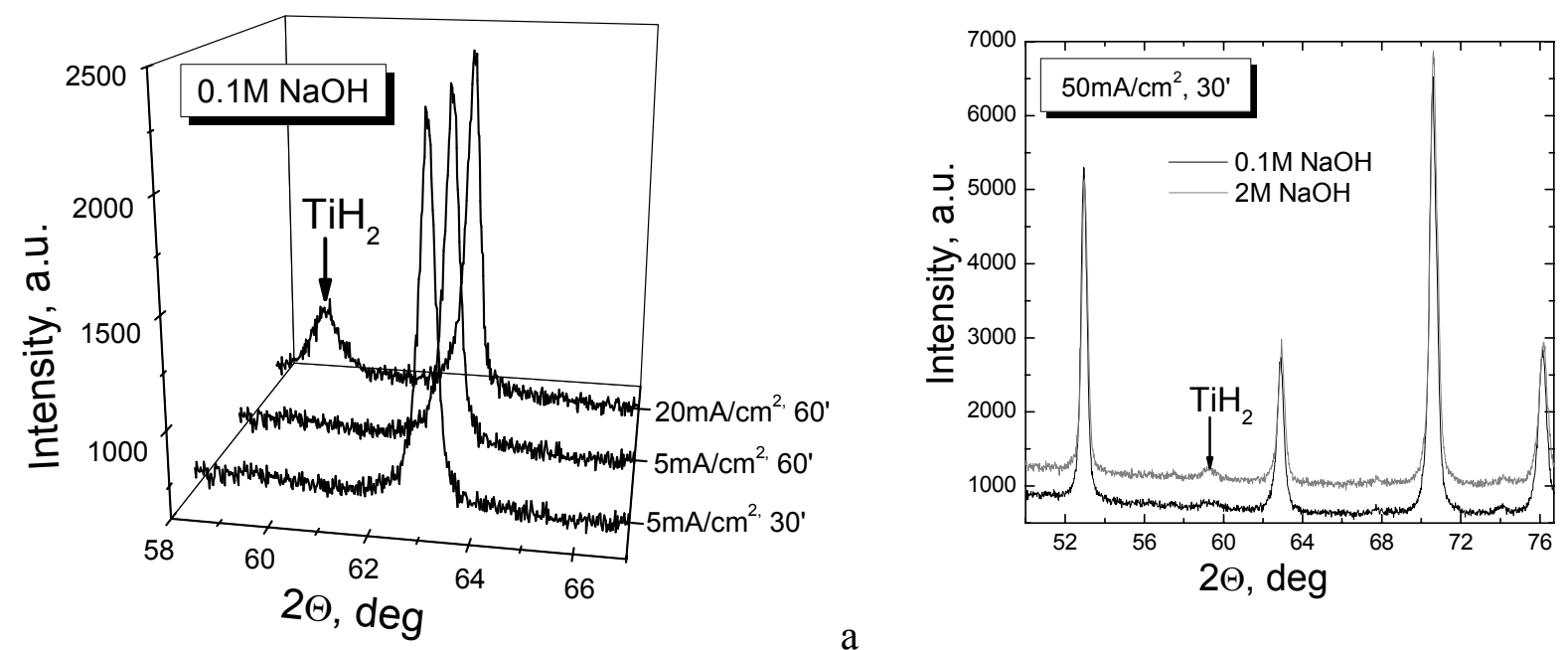

Fig. 5. Effect of the time of hydrogen charging and the applied cathodic polarization (a) and effect of the solution concentration (b) on the formation of the hydride phase

According to the JCPDS PDF-2/2001 database [8] the formed hydride phase corresponds to the hydride $\mathrm{TiH}_{2}$ of tetragonal structure (file 09.0371) with the lattice parameter $\boldsymbol{a}=3.12 \AA$ and $\boldsymbol{c}=4.18 \AA$. In the studied case, the lattice parameter $\boldsymbol{a}$ of the hydride changes at increase cathodic polarization in $0.1 \mathrm{M} \mathrm{NaOH}$, and have been measured as being $3.1161 \AA$ Á, $3.1173 \AA$ and $3.1244 \AA$ at polarization $10 \mathrm{~mA} / \mathrm{cm}^{2}, 400 \mathrm{~mA} / \mathrm{cm}^{2}$ and $1250 \mathrm{~mA} / \mathrm{cm}^{2}$, respectively. Because of the low intensity of appropriate diffraction lines, the lattice parameter $c$ of hydride cannot be calculated with the good accuracy for the studied materials.
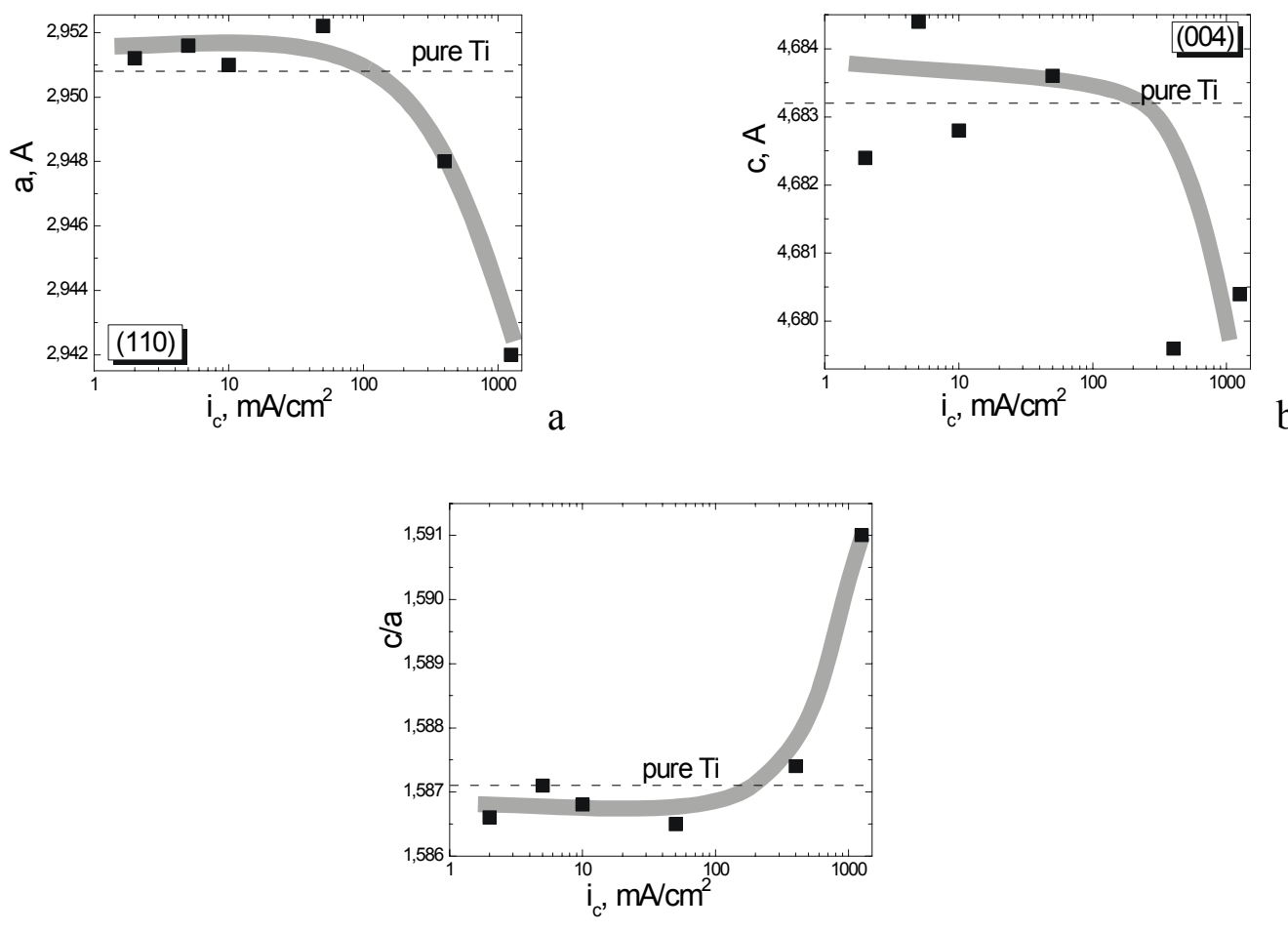

Fig. 6. Effect of cathodic polarization in $0.1 \mathrm{M} \mathrm{NaOH}$ for 30 min on lattice parameters (a, b) and tetragonality (c)of the $\alpha$-Ti lattice

The hydrogen charging affects the state of the $\alpha$-Ti lattice. At the low cathodic polarization, the both lattice parameters $(\boldsymbol{a}$ and $\boldsymbol{c}$ ) are slightly larger in comparison with the as received $\mathrm{Ti}$, whereas increase in polarization above about $200 \mathrm{~mA} / \mathrm{cm}^{2}$ causes the substantial 
decrease in both parameters (Fig. 6a and 6b). The ratio of $\boldsymbol{c} / \boldsymbol{a}$ in the material mildly cathodically charged is slightly lower than that in pure $\mathrm{Ti}$, but drastically increases at polarization above $200 \mathrm{~mA} / \mathrm{cm}^{2}$, cf. Fig. $6 \mathrm{c}$.
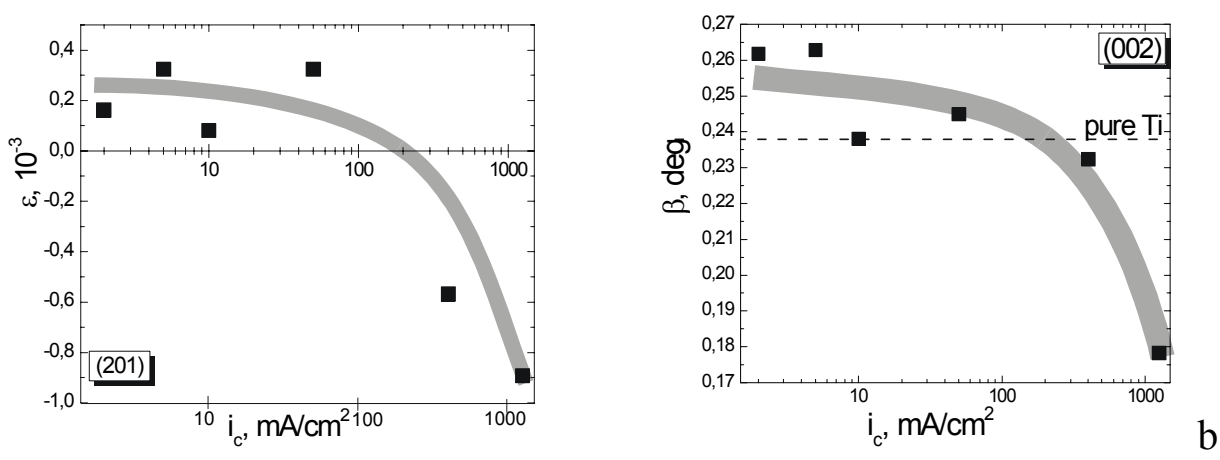

$\mathrm{a}$

Fig. 7. Effect of cathodic polarization in $0.1 \mathrm{M} \mathrm{NaOH}$ for 30 min on the straining of $\mathrm{Ti}$ (a) and on the width of the Ti diffraction line (b)

The straining of the $\alpha$-Ti lattice due to the hydrogen charging as calculated according to equation (1) is shown in Fig. 7a. At polarization below $200 \mathrm{~mA} / \mathrm{cm}^{2}$, the hydrogen causes the expansion of lattice, whereas at much higher cathodic polarization, the lattice compression takes place. Fig. $7 \mathrm{~b}$ shows that the hydrogen charging at low cathodic polarization expands the diffraction lines width, whereas high cathodic polarization causes their shrinking.

\section{DISCUSSION}

In accordance with the data obtained in [16], the cathodic polarization of $\alpha$-Ti from the more concentrated electrolyte causes the higher hydrogen charging: in $2 \mathrm{M} \mathrm{NaOH}$ solution, the hydride phase has been formed at the lowest applied cathodic polarization. In the case of $0.1 \mathrm{M} \mathrm{NaOH}$, the several ranges of cathodic polarization differently affecting the hydrogen behavior may be distinguished. Fig. 8 compares the height of the $650^{\circ} \mathrm{C}$ hydrogen extraction peak, the intensity of the hydride diffraction line and the lattice parameter of hydride at application of increased polarization.

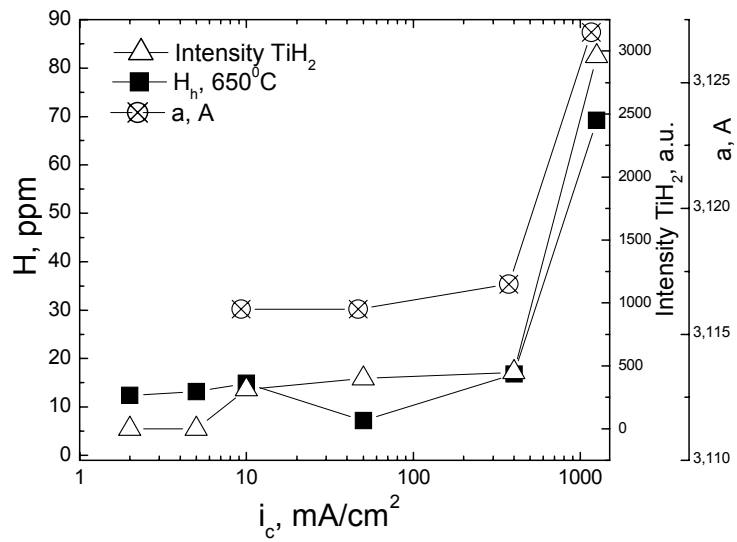

Fig. 8. Comparison of the change of the height of the high temperature extraction peak, the intensity of the hydride diffraction line and the lattice parameter of the formed hydride phase in the course of increased cathodic polarization in $0.1 \mathrm{M} \mathrm{NaOH}$ 
The above parameters reveal the amount and the state of absorbed hydrogen $[10,11]$, the presence and the amount of hydride phase and the stoichiometry of the formed hydride [7], respectively.

It is seen that at polarization lower than about $5 \mathrm{~mA} / \mathrm{cm}^{2}$ no hydride is formed, whereas the massive formation of hydride occurs at cathodic polarization above $200 \mathrm{~mA} / \mathrm{cm}^{2}$ in $0.1 \mathrm{M} \mathrm{NaOH}$ solution.

From the processing of the obtained hydrogen extraction spectra, the differently bound hydrogen can be evaluated. The formation of extraction peak at $550-650^{\circ} \mathrm{C}$ has been accounted in $[6,11]$ for the dissolution of hydride. The broadening of the peak and its shift to the lower temperature have been explained by the extraction of hydrogen trapped by the structural defects of high concentration. However, in [10] the peak at about $200^{\circ} \mathrm{C}$ has been attributed to hydride dissolution, whereas the peak formed at about $650^{\circ} \mathrm{C}$ has been explained by the extraction of hydrogen deeply trapped at defects induced by the hydride formation. The similar explanation of the nature of the subsequent extraction peaks have been also done for aluminides [23, 24].

In the studied case the substantial increase in the height of the $650^{\circ} \mathrm{C}$ extraction peak occurs at the high cathodic polarization and correlates with the distinct increase in the intensity of the diffraction lines and hence with the distinct increase in the amount of hydride (Fig. 8). This may suggest that the $650^{\circ} \mathrm{C}$ peak corresponds to the extraction of hydrogen from the decomposed hydride phase, in agreement with the suggestions done in $[6,11]$. However, the $650^{\circ} \mathrm{C}$ peak has been observed on the extraction spectra at polarization lower than that corresponding to the formation of hydride phase, cf. Fig 1. It has been suggested [25, 26] that the precipitation of the hydride phase has been preceded by the formation of some precursors or the areas of defected lattice supersaturated with hydrogen. Therefore, the high temperature peak observed in metal not reveling the hydride phase may be associated with the hydrogen extraction from those areas. However, the more precise studies are of an interest.

The low temperature peak already observed at the low cathodic polarization (Fig. 3) should be associated with the hydrogen dissolved in the $\alpha$-Ti lattice. It is interesting to note that the hydrogen content in the $\alpha$-Ti lattice decreases when cathodic polarization produces the formation of hydride (cf. Figs 3 and 4b). This may reveal the depletion of the solid solution with hydrogen at the hydride precipitation.

Within the intermediate polarization region the hydrogen exists as dissolved in the metal lattice and as that forming the hydride precipitates. The hydrogen ingress changes the state of the $\alpha$-Ti lattice due to the formation of solid solution. Dissolved hydrogen increases the lattice parameters (Figs. 6a and $6 \mathrm{~b}$ ) but slightly decreases the $c / a$ ratio (Fig. $6 \mathrm{c}$ ). This may be accounted for the occupation of the tetrahedral holes in $\alpha$-Ti lattice by incorporated hydrogen atoms, in accordance with $[1,3]$. As a result, the lattice becomes slightly flattened despite its expansion (Fig. 7a). The metal straining within the low and intermediate regions of polarization may also suggest the increase in the width of diffraction lines, since the widening of the lines corresponds to the decrease in the size of the areas of the coherent scattering [22]. As follows from Fig. 8, the amount and the stoichiometry of the formed hydride phase remain roughly nonaffected by the increase in polarization within the intermediate polarization region.

At the high cathodic polarization, the massive formation of hydride phase has been accompanied by the change of its stoichiometry [7] as follows from the increase in the hydride lattice parameter cf. Fig. 8. The intensive formation of hydride results in the deformation of the $\alpha$-Ti lattice (Fig. 6c). Because of the big difference (up to $23 \%$ [27]) between the lattice volume of $\alpha$-Ti and hydride, the hydride formation should introduce the stresses within the metal. Indeed the compression of the $\alpha$-Ti lattice (Fig. 7a) has been observed at the high cathodic polarization. The observed decrease in the diffraction line width 
(Fig. 7b) corresponding to the increase in the size of the areas of coherent scattering may suggest that the hydride precipitates of crystallographic orientation [7, 13] produce some dislocation ordering within the stressed $\mathrm{Ti}$.

The more pronounced changes of the Ti lattice occurred at still increased polarization might be the result of increased amount of hydride phase and of increased lattice parameters of hydride, as well.

\section{CONCLUSIONS}

1. Electrochemical parameters have been established allowing obtain (i) the hydrogen in the solid solution in $\alpha-\mathrm{Ti}$, (ii) the precipitation of hydride and (iii) the massive formation of the hydride phase.

2. The hydrogen dissolved in the lattice as well as that formed the hydride phase affect the $\alpha$-Ti lattice parameters and its strain state.

3. Formation of the hydride phase causes the specific distortion of the metal lattice.

4. Possibility of hydride formation at similar cathodic polarization increases at increase in the solution concentration.

5. Increase in the hydrogen content affects the stoichiometry of the formed hydride.

6. Different effects of hydrogen on the elastic and plastic behavior of the $\alpha$-Ti may be obtained at application of the proper electrochemical parameters.

\section{ACKNOWLEDGEMENT}

The present study has been has been carried out at financial support provided by the grant 3T08C02630.

\section{REFERENCES}

1. Haag R.M., Shipko F.J.: The titanium - hydrogen system. J.Amer. Chem. Soc. 78 (1965), pp. 5156-5159.

2. Livanov W.A., Bukhanova A.A., Kolachev B.A.: Vodorod w titane. Gos. Nauchnotekhnich. izdatelstvo literatury po chernoj i cvetnoj metalurgii, Moskva, 1962.

3. Azarkh Z.M., Gavrilov P.I.: Strukturnyje izmenenija gidtrida titana pri bolshikh koncentraciakh vodoroda. Kristallografija 15 (1970), pp. 275-279.

4. Philips I.I., Poole P., Shreir L.L.: Hydride formation during cathodic polarization of Ti - I. Effect of current density on kinetics of growth and composition of hydride. Corrosion Sci. 12 (1972), pp. 855-866.

5. Borchers C.H., Leonov A.V., Khomrnko T.I., Morozova O.S.: Mechanism and kinetics of mechanically induced transformation of Ti and titanium hydride: Effect of 
reaction medium on microstructure, morphology and hydrogen-uptake properties. J. Materials Sciences 39 (2004), pp. 5259-5262.

6. Schur D.V., Zaginajchenko S.Y., Adejev V.M., Voitovich V.B., Lyashenkov A.A., Trefilov V.I.: Phase transformation in titanium hydrides. Int. J. Hydrogen Energy 21 (1996), pp. 1121-1124.

7. Irving P.E., Beevers C.J.: Some metallographic and lattice parameter observations on titanium hydride. Metalurg. Trans. 2 (1971), pp. 613-615.

8. JCPDS PDF-2/2001 database

9. Trefilov V.I., Timofeeva I.I., Klochkov L.I., Morozov I.A., Morozova R.A.: Effects of temperature change and hydrogen content on titanium hydride crystal lattice volume. Int. J. Hydrogen Energy 21 (1996), pp. 1101-1103.

10. Toshio Ogawa, Ken'ichi Yokoyama, Kenzo Asaoka, Jun'ichi Sakai: Distribution and thermal desorption behavior of hydrogen in titanium alloys immersed in acidic fluoride solutions. J. Alloys and Compounds 396 (2005), pp. 269-274.

11. Tal-Gutelmacher E., Eliezer D.: High fugacity hydrogen effects at room temperature in titanium based alloys. J. Alloys and Compounds 404-406 (2005), pp. 613-616.

12. Briant C.L., Wang Z.F., Chollocoop N.: Hydrogen embrittlement of commercial purity titanium. Corrosion Science 44 (2002), pp. 1875-1888.

13. Forolius Z.A.: Factors influencing absorption of hydrogen in titanium from aqueous electrolytic solutions. Proc of $4^{\text {th }}$ Conference Titanium-80. Sciences and Technology, Kyoto, Japan, 1980, H.Kimura, O.Izumu Eds., Publ. The Metall. Soc. Of AIME, 1980, NY, pp. 2705-2711.

14. Łunarska E., Zaborski S.: Tworzenie się fazy wodorkowej podczas obróbki elektrochemiczno-ściernej stopu tytanu. Prace I Ogólnopolskiej Konferencji Naukowej „Nowoczesne technologie w inżynierii powierzchni”, Łódź, wrzesień 1999, str. 425-428.

15. Lunarska E., Zaborski S.: Hydrogen effects in anodic grinding of Ti alloy. Wear 249 (2001), pp. 606-616.

16. Katsutoshi Takashima, Ken'ichi Yokoyama, Kenzo Asaoka, Jun'ichi Sakai: Effects of potential on hydrogen absorption and desorption behaviors of titanium in neutral fluoride solutions. J. Alloys and Compounds 431 (2007), pp. 203-207.

17. Zaborski S.: Elektrochemiczna intensyfikacja obróbki ściernej materiałów trudno obrabialnych. Oficyna Wyd. Politechniki Wrocławskiej, Wrocław, 2000.

18. Senkov O.N., Dubois M., Jonas I.J.: Elastic moduli of titanium-hydrogen alloys in the temperature range $20^{\circ} \mathrm{C}$ to $1100^{\circ} \mathrm{C}$. Met. And Mater. Trans. A29 (1996), pp. 39633970 .

19. Daigo Setayama, Junji Matsumaga, Hiroaki Muta, Masayohi Uno, Shinsuke Yamanaka: Mechanical properties of titanium hydride, Inetrn. J. Alloys and Compounds, 381 (2004) pp. 215-220

20. Brass A.M., Chene J.: Hydrogen absorption in titanium aluminides exposed to aqueous solutions at room temperature. Materials Sciences and Engineering A272 (1999), pp. 269-278. 
21. Polyanskiy A.M., Polyanskiy V.A., Popov-Diumin D.B.: The use of the analyzer AV1 for studying dynamics of high-temperature vacuum extraction of hydrogen from metallic probes. Materialovedenie 98 (2005), pp. 51-54.

22. Bojarski Z., Łagiewka E.: Rentgenowska analiza strukturalna. Wydawnictwo Uniwersytetu Śląskiego, Katowice, 1995.

23. Takasaki A., Furuya Y., Ojima K., Taneda Y.: Hydrogen evolution from cathodically charged two-phase $\left(\mathrm{Ti}_{3} \mathrm{Al}+\mathrm{TiAl}\right)$ titanium aluminides. J. Alloys and Compounds 224 (1995), pp. 299-304.

24. Takasaki A., Homma T.: Hydrogen evolution from cathodically charged titanium aluminide alloy Ti-24Al-Nb. J. Alloys and Compounds 340 (2002) pp. 127-131.

25. Spivak L., Skriabina N.: Effekt plasticheskogo prevrashchenia i pamiati formy v Zr-H, Fizyka Metallov i Metallovedenie, 81 (1996) pp. 176-171.

26. Spivak L., Lunarska E.: The effect of hydrogen in the shear modulus of polycrystalline aluminium, Technical Physics Letters, 32 (2006) pp. 55-57.

27. Christodoulou L., Clarke I.A.: Hydrogen effects on fracture toughness of XD titanium aluminide. Hydrogen Effects on Materials Behavior. N.R.Mondy, A.W.Thompson [eds.], Mineral, Metals \& Materials Soc., 1990, pp. 515-522. 